\title{
Importância da aplicação da Avaliação Ambiental Estratégica (AAE) no ordenamento jurídico brasileiro
}

\section{The importance of implementing the strategic environmental assessment (SEA) in Brazilian jurisdiction}

Heloise Siqueira Garcia ${ }^{1}$ Denise Schmitt Siqueira Garcia²
Mestranda do Programa de Pós Graduação Stricto Sensu em Ciência Jurídica - PPCJ - UNIVALI. Bolsista no Programa de Suporte à Pós-Graduação de Instituições de Ensino Particulares - PROSUP - CAPES. Graduada em Direito pela Universidade do Vale do Itajaí - UNIVALI. Advogada.

Doutora pela Universidade de Alicante na Espanha. Mestre em Derecho Ambiental y Sostenibilidad pela Universidade de Alicante na Espanha. Mestre em Ciência Jurídica. Especialista em Direito Processual Civil. Professora do Programa de Pós graduação stricto sensu em Ciência Jurídica, de pós graduação lato sensu e da graduação. Coordenadora de pós graduação lato sensu em Direito Processual Civil da Universidade do Vale do Itajaí. Advogada.

\section{Resumo}

Crescente é a preocupação com a efetivação da proteção ambiental diante do crescimento da conscientização da sociedade a respeito do meio ambiente que os circunda e da necessidade de sua manutenção para uma efetiva vida na Terra. Para tanto surgem diversos instrumentos a serem seguidos para instalação de atividades que possam ser degradantes ao meio ambiente, encaixando-se o presente artigo como modo de apresentar um novo instrumento regulador que ainda não é regulamentado em lei específica no Brasil. $\mathrm{O}$ artigo terá como objeto a análise da possível aplicação da Avaliação Ambiental Estratégica (AAE) no ordenamento jurídico brasileiro. Tendo como objetivo geral ANALISAR a importância do instituto da AAE e sua necessidade de inclusão no ordenamento jurídico brasileiro, e objetivos específicos CONCEITUAR o instituto da Avaliação de Impacto Ambiental; DEMONSTRAR os conceitos e requisitos do Estudo de Impacto Ambiental (EIA); e IDENTIFICAR o conceito, os requisitos e a aplicabilidade da Avaliação Ambiental Estratégica (AAE). Na metodologia foi utilizado o método indutivo na fase de investigação; na fase de tratamento de dados o método cartesiano e no relatório da pesquisa a base indutiva. Foram também acionadas as técnicas do referente, da categoria, dos conceitos operacionais, da pesquisa bibliográfica e do fichamento.

Palavras-chave: Avaliação Ambiental Estratégica. Estudo de Impacto Ambiental. Direito Ambiental.

\section{Abstract}

The concern about the effectiveness of environmental protection is growing up in face of the growing awareness of society regarding the environment that surrounds them and the need for effective maintenance life on Earth. For that arise various instruments to be followed for installation of activities that may be degrading the environment, fitting into this article as a way to introduce a new regulatory instrument that is not yet regulated by a specific law in Brazil. The article has the purpose of analyzing the possible application of the Strategic Environmental Assessment (SEA) in the Brazilian legal system. Aiming to EXAMINE the significance of the SEA and its need for inclusion in the Brazilian legal system, and specific goals CONCEPTUALIZE the Institute of Environmental Impact Assessment; DEMONSTRATE the concepts and requirements of the Environmental Impact Study (EIS) and IDENTIFY the concept, requirements and applicability of the Strategic Environmental Assessment (SEA). At the methodology was used the inductive method ate the research phase; at the data processing the Cartesian method and at the research report the inductive base. Were also triggered the techniques of referent, category, operational concepts, literature research and book report.

Keywords: Strategic Environmental Assessment. Environmental Impact Study. Environmental Law. 


\section{Introdução}

$\mathrm{O}$ artigo tem por objetivo compreender a importância da aplicação da Avaliação Ambiental Estratégica (AAE) no ornamento jurídico brasileiro como um novo instrumento regulador que ainda não é regulamentado na forma de lei específica no Brasil, mas que possui efetividade em outros países e visa garantir o manutenção do meio ambiente sustentável.

A escolha do tema se deu a partir da observação de comentários favoráveis em doutrinas que tratam de Direito Ambiental, que ao abordarem a Avaliação de Impacto Ambiental (AIA), discorrem sobre a aplicação da Avaliação Ambiental estratégica (AAE), sendo que a grande maioria comenta da importância deste instrumento ser aplicado no ordenamento jurídico brasileiro. Inclusive observou-se que tramita no Senado Federal Projeto de Lei que visa a sua implementação (PL n ${ }^{\circ} .2072$ de 2003).

O desenvolvimento do artigo se dará primordialmente no âmbito do Direito Ambiental, em que se buscará analisar em doutrinas ambientalistas, tanto brasileiras quanto estrangeiras, a conceituação da Avaliação Ambiental Estratégica (AAE) e como se dá sua aplicação nos países em que tal instrumento é utilizado, destacando sempre a importância de sua possível aplicação no ordenamento jurídico brasileiro.

Serão usadas, também, outras fontes que possam discorrer sobre o assunto, como periódicos e artigos científicos.

Nessa perspectiva, este artigo terá como objeto a análise da possível aplicação da Avaliação Ambiental Estratégica (AAE) no ordenamento jurídico brasileiro, destacando sua importância para a manutenção do meio ambiente sustentável.

Tem como objetivo geral ANALISAR a importância do instituto da Avaliação Ambiental Estratégica (AAE) e sua necessidade de inclusão no ordenamento jurídico brasileiro. E como objetivos específicos CONCEITUAR o instituto da Avaliação de Impacto Ambiental; DEMONSTRAR os conceitos e requisitos do Estudo de Impacto Ambiental (EIA); e IDENTIFICAR o conceito, os requisitos e a aplicabilidade da Avaliação Ambiental Estratégica (AAE).

Portanto como problemas centrais serão enfocados os seguintes questionamentos: Qual a importância da inserção no ordenamento jurídico brasileiro da Avalia- ção Ambiental Estratégica? Qual a diferença, vantagens e desvantagens da Avaliação Ambiental Estratégica e do Estudo de Impacto Ambiental?

Para tanto, o artigo foi dividido em três partes: a primeira trata sobre o instituto da Avaliação de Impacto Ambiental no Brasil, da qual se desdobrou um subitem: a Avaliação de Impacto Ambiental como gênero e sua relação com o Estudo de Impacto Ambiental; a segunda parte trata da importância da Avaliação Ambiental Estratégica, a qual apresenta, também, dois subitens: considerações dos países e estados brasileiros que já utilizam a Avaliação Ambiental Estratégica e considerações das vantagens da implementação da Avaliação Ambiental Estratégica; por fim o último item trata da possibilidade da aplicação da Avaliação Ambiental Estratégica no ordenamento jurídico brasileiro.

$\mathrm{Na}$ metodologia foi utilizado o método indutivo na fase de investigação; na fase de tratamento de dados o método cartesiano e no relatório da pesquisa a base indutiva. Foram também acionadas as técnicas do referente, da categoria, dos conceitos operacionais, da pesquisa bibliográfica e do fichamento.

\section{0 instituto da avaliação de impacto ambien- tal no Brasil}

Pode-se dizer que na sociedade em que se vive atualmente a preocupação com o meio ambiente e com todos os impactos neles já causados, assim como os que serão futuramente causados, é latente, sendo que cada vez mais se procura discutir acerca do Direito Ambiental e dos meios que possam, de alguma forma, garantir a preservação ambiental.

Toda essa preocupação se deu a partir da evolução do homem, da ciência e da tecnologia, da sua ganância natural em sempre querer mais e buscar o desenvolvimento a qualquer custo.

Isso consegue ser claramente observado na evolução do Estado de Direito, ao passar pelas suas três fases: Estado Liberal de Direitos, Estado Social de Direito e Estado Democrático de Direitos, o que se encontra a sociedade atual, apesar de muitos entenderem que tal Estado ainda não foi alcançado plenamente, estando a sociedade numa fase de transição e busca.

Nesse Estado em que se vive atualmente, ou que se busca viver, verifica-se a recente e crescente preocupação com o meio ambiente, valorizando-se os direitos difusos 
e tendo como carro chefe o próprio Meio Ambiente. Para tanto, cada vez mais são buscadas técnicas que visem assegurar o bom mantenimento deste. Essas técnicas dividem-se de diversas formas, as quais buscam primordialmente avaliações para que o desenvolvimento econômico e social atual não influencie ainda mais de forma negativa o meio ambiente.

Porém, deve-se sempre ter em mente que o desenvolvimento econômico e social é algo que não vai e não deve parar, e consequentemente diversos impactos serão gerados, de modo que se deve pensar ainda mais amplamente na implementação de políticas públicas que visem garantir a correta instalação de empreendimentos para que sejam gerados o menor número de impactos ambientais possíveis.

Nesse contexto, para a efetivação concreta dessa proteção ambiental, existe a necessidade de instrumentos regulamentados a serem seguidos para instalação de atividades que possam ser degradantes do meio ambiente, instrumentos que serão tratados no presente artigo.

Na medida em que evoluíram os conceitos que resultaram na formulação desse novo ramo do direito, o conhecimento e a avaliação dos impactos deram origem a um instrumento fundamental, com vistas a prevenir danos futuros e, ainda, na incerteza científica de que os danos não serão irreversíveis, não autorizar a atividade com base no princípio da precaução. ${ }^{3}$

Deve-se sempre desenvolver atenção especial quanto aos impactos ambientais de determinadas atividades, de modo a se evitar os impactos negativos, conforme comenta Paulo de Bessa Antunes ${ }^{4}$ ao conceituar Impacto Ambiental: "[...] é um abalo, uma impressão muito forte, muito profunda, causada por motivos diversos sobre o ambiente, isto é, sobre aquilo que cerca ou envolve os seres vivos. Se forem positivos, devem ser estimulados; se forem negativos, devem ser evitados." ${ }^{5}$

GRANZIERA, Maria Luiza Machado. Direito ambiental. São Paulo: Atlas, 2009. p. 279.

4 ANTUNES, Paulo de Bessa. Direito ambiental. 9. ed. Rio de Janeiro: Lumen Júris, 2006. p. 257.

5 Considerando-se ainda um conceito jurídico de Impacto Ambiental, pode-se destacar o presente no artigo $1^{\circ} \mathrm{da}$ Resolução ${ }^{\circ}$. 1/86 do Conselho Nacional do Meio Ambiente (CONAMA): "Impacto Ambiental é qualquer alteração das propriedades físicas, químicas e biológicas do meio ambiente, causada por qualquer forma de matéria ou energia resultante das atividades humanas que, direta ou indiretamente, afetam: I - a saúde, a segurança e o bem-estar da população; II - as atividades sociais e econômicas; III - a biota; IV - as condições estéticas e sanitárias do meio am-
Por todas essas considerações, deve-se ter em mente o que atualmente é regulado e implementado no Brasil, assim como sempre traçar comentários e considerar técnicas que visem garantir a manutenção de um meio ambiente de qualidade e diminuir os impactos ambientais de diversas atividades e empreendimentos.

Tendo em vista o contexto brasileiro atual a primeira consideração que deve ser feita é quanto a Avaliação de Impacto Ambiental (AIA), sendo este um instrumento abrangente, inserido pela Política Nacional do Meio Ambiente (PNMA) - Lei 6.938/81 - em seu artigo 9, inciso III; aprovado pela Resolução nº. 01/86 do Conselho Nacional do Meio Ambiente (CONAMA); e também tratado na Declaração do Rio de 1992, estabelecido como um de seus princípios.

"Por instrumento da Política Nacional do Meio Ambiente deve ser entendido todo o mecanismo de que dispõe o Estado ou a sociedade para auxiliar ou levar a efeito as ações de efetiva proteção ambiental." 6

A se iniciar, então, pela Política Nacional do Meio Ambiente, tem-se a estipulação no artigo $9^{\circ}$ de quais seriam seus instrumentos, estando a Avaliação de Impactos Ambientais prevista no inciso III do referido diploma:

Art. 9. São instrumentos da Política Nacional do Meio Ambiente: [...]

III - a avaliação de impactos ambientais; [...]

Dando seguimento, a Declaração do Rio de 1992, em seu princípio 17, traz também considerações:

Princípio 17: Deverá ser empreendida a avaliação de impacto ambiental, em termos de instrumento nacional, a despeito de qualquer atividade proposta que provavelmente produza impacto negativo considerável e que esteja sujeita à decisão de uma autoridade nacional competente. $^{7}$

Nesse sentido Édis Milaré ${ }^{8}$ conceitua a Avaliação de Impacto Ambiental como sendo:

[...] um meio de atuação preventiva, que visa evitar as consequências danosas, sobre o meio ambiente, de um projeto de obras, ou de qualquer atividade. Seu objetivo central é evitar que

biente; V - a qualidade dos recursos ambientais."

$6 \quad$ SILVA, Américo Luís Martins. Direito do meio ambiente e dos recursos naturais. São Paulo: RT, 2004. v. 1. p. 517.

7 DECLARAÇÃO do Rio sobre meio ambiente e desenvolvimento. Rio de Janeiro, 1992. Disponível em: <http://www. ufa.br/npadc/gpeea/DocsEA/DeclaraRioMA.pdf $>$ Acesso em: 20 de março de 2012.

8 MILARÉ, Edis. A importância dos estudos de impacto ambiental. São Paulo: RT, 1988. p. 251. 
um projeto (obra ou atividade), justificável sob o prisma econômico ou em relação aos interesses imediatos de seu proponente, se revele posteriormente nefasto ou catastrófico para o meio ambiente. Valoriza-se, na plenitude, a vocação essencialmente preventiva do Direito Ambiental, expressa no conhecido apotegma: é melhor prevenir do que remediar (miex vaut prevenir que guérir).

Ainda denota-se que tal instituto é também aplicado no direito espanhol, assim como em outros países, sendo que naquele assume a sigla EIA, decorrente de Evalución del Impacto Ambiental, e nesse contexto o doutrinador Estevan Bolea ${ }^{9}$ o conceitua conforme os seus termos:

En primer lugar, evalución que es la acción o el efecto de evaluar, que significa "estimar, apreciar, calcular el valor de una cosa". Esa "cosa" que se evalúa es el impacto ambiental. Impacto es el "efecto de una fuerza aplicada bruscamente". El impacto ambiental de un proyecto se puede definir como "la diferencia de la situación del medio ambiente futuro modificado", tal y como resultaría después de la realización del proyecto, y la situación del medio ambiente futuro, tal como habría evolucionado normalmente sin tal actuación.

Também ressalta Ramón Martin Mateo ${ }^{10}$ que

[...] una EIA puede ser definida en su formulación moderna como un proceso por el cual una acción que debe ser aprobada por una autoridad pública y que puede dar lugar a efectos colaterales significativos para el medio, se somete a una evaluación sistemática cuyos resultados son tenidos en cuenta por la autoridad competente para conceder o no su probación.

Assim contextualizando pode-se observar a importância do instituto da Avaliação de Impacto Ambiental, sendo que seu objetivo primordial é analisar os impactos que determinado empreendimento poderá acarretar, tendo maior certeza da viabilidade de realização ou não de tal empreendimento.

Américo Luís Martins da Silva ${ }^{11}$ nesse sentido salienta seus objetivos primordiais como sendo "[...] identificar, predizer e descrever, em termos apropriados, os prós e os contras - danos e benefícios - de uma proposta de desenvolvimento [...]".

ESTEVAN BOLEA, M. T. Evalución del impacto ambiental. Madrid: ITSEMAP (MAPFRE), 1989.

10 MARTÍN MATEO, Ramón. Tratado de derecho ambiental. Madrid: Editorial Trivium, 1991. 1. v. p. 301.

11 SILVA, Américo Luís Martins. Direito do meio ambiente $e$ dos recursos naturais. São Paulo: Revista dos Tribunais, 2005. p. 518.
Por tais argumentações, pode-se observar ser a Avaliação de Impacto Ambiental instrumento genérico da PNMA, pois sequer possui regulamentação específica, além de seus conceitos e objetivos serem bastante amplos perante as realidades práticas.

Desse modo, após estudo realizado em referencial teórico, as autoras compreenderam por considerar que a Avaliação Ambiental Estratégica como um instrumento genérico no ordenamento jurídico brasileiro, da qual decorrem algumas espécies, conforme melhor se explana no subitem a seguir.

\subsection{A Avaliação de Impacto Ambiental - AIA como gênero e sua relação com o Estudo de Impacto Ambiental - EIA}

Vale considerar que a Avaliação de Impacto Ambiental é gênero, do qual se desdobram diversas espécies, muitas delas observadas no Brasil, como por exemplo, o Estudo de Impacto Ambiental, o Estudo de Viabilidade Ambiental, o Relatório Preliminar Ambiental e o Relatório do Controle Ambiental, porém outras não, como é o caso da Avaliação Ambiental Estratégica, foco principal do presente artigo.

Considerando-se, então, o tema principal proposto para o artigo, importante são algumas considerações acerca do Estudo de Impacto Ambiental ${ }^{12}$, sendo este instituto o que mais se liga à Avaliação Ambiental Estratégica, porém o que possui diferenças consideráveis.

Coadunando, então, com a ideia de que a Avaliação de Impacto Ambiental é gênero do qual se depreendem diversas espécies, pode-se encontrar pensamento convergente com Edis Milaré ${ }^{13}$ e Felipe Campanha Demarchi e Flavia Trentini ${ }^{14}$, estes últimos ainda desenvolvem o seguinte entendimento:

Logo, constitui mais um dos instrumentos jurídicos de natureza preventiva criados com o objetivo de enfrentar o problema da degradação ambiental. Este instrumento de identificação de riscos e danos deverá ser utilizado para

12 Alguns doutrinadores utilizam a nomenclatura Estudo Prévio de Impacto Ambiental (EPIA).

13 MILARÉ, Edis. Direito do ambiente: doutrina, prática, jurisprudência, glossário. 2. ed. São Paulo: RT, 2001. p. 490.

14 DEMARCHI, Felipe Camapnha; TRENTINI, Flávia. Estudo de impacto ambiental: apreciação crítica sobre a sua efetividade. In: BENJAMIM, Antonio Herman. (Org.) Anais do Congresso Brasileiro de Direito Ambiental. PNMA: 30 anos da Política Nacional de Meio Ambiente. São Paulo: Imprensa Oficial do Estado de São Paulo, 2011. 3. v. 
qualquer tipo de atividade ou obra efetiva ou potencialmente poluidora, a fim de possibilitar que sejam adotadas medidas preventivas e corretivas dos eventuais danos ambientais que poderão surgir nas fases de instalação e operação da atividade. ${ }^{15}$

Destacando Édis Milaré ${ }^{16}$ a necessidade de se ver clara a diferença entre o gênero e a espécie Estudo de Impacto Ambiental, que muitas vezes são confundidos por até mesmo entidades do Poder Público:

[...] a AIA não pode ser reduzida a uma de suas modalidades, isto é, ao EIA/RIMA. Em outro modo de dizer, deixou-se claro que o EIA é espécie do gênero "estudos ambientais", ou, como preferimos, da "avaliação de impactos ambientais”. Também, de que ele é exigível somente quando houver risco de significativa degradação ambiental, risco esse presumível, salvo prova em contrário, para as atividades relacionadas no art. $2^{\circ}$ da Resolução CONAMA 001/86.

Por ser espécie da Avaliação de Impacto Ambiental, pode-se dizer que o Estudo de Impacto Ambiental também é instrumento da PNMA conforme o disposto no artigo $9^{\circ}$, inciso III, da Lei 6.938/81, sendo que terá como objeto avaliar as proporções das possíveis alterações que um empreendimento, público ou privado, pode ocasionar ao meio ambiente.

O EIA será sempre um procedimento público, não podendo ser entendido como sendo "[...] um estudo privado efetuado por uma equipe multidisciplinar sob encomenda do proponente do projeto, uma vez que é imprescindível a intervenção inicial do órgão público ambiental desde o início do procedimento." ${ }^{\text {17 }}$

Paulo Bessa Antunes ${ }^{18}$ acrescenta comentando que seria medida praticada somente pelo Poder Executivo, "A exigência de estudos de impacto ambiental, ou de qualquer outra forma de avaliação de impacto ambiental é medida tipicamente administrativa e, portanto, praticada apenas pelo Poder Executivo." E continua seu raciocínio confirmando que sua natureza jurídica seria constitucional, constituído

15 DEMARCHI, Felipe Camapnha; TRENTINI, Flávia. Estudo de impacto ambiental: apreciação crítica sobre a sua efetividade. In: BENJAMIM, Antonio Herman. (Org.) Anais do Congresso Brasileiro de Direito Ambiental. PNMA: 30 anos da Política Nacional de Meio Ambiente. São Paulo: Imprensa Oficial do Estado de São Paulo, 2011. 3. v. p. 614.

16 MILARÉ, Edis. Direito do ambiente: doutrina, prática, jurisprudência, glossário. Local: editora, ano. p. 490.

17 MACHADO, Paulo Affonso Leme. Direito ambiental brasileiro. 18. ed. São Paulo: Malheiros, 2010. p. 235.

18 ANTUNES, Paulo de Bessa. Direito ambiental. 9. ed. Rio de Janeiro: Lumen Júris, 2006. p. 281. como instrumento da Política Nacional do Meio Ambiente.

$\mathrm{Na}$ condição de instrumento constitucional da Política Nacional do Meio Ambiente - PNMA, o EIA tem por finalidade precípua auxiliar, como fonte de informação técnica, a consecução plena e total dos objetivos fixados pela Política Nacional do Meio Ambiente, conforme fixado na Lei $\mathrm{n}^{\circ}$. 6.938/81. ${ }^{19}$

Tendo em vista sua conceituação, Larry W. Can$\operatorname{ter}^{20}$ o considera como sendo "[...] la identificación y valoración de los impactos (efectos) potenciales de proyectos, planes, programas o acciones normativas relativos a los componentes físico-químicos, bióticos, culturales y socioeconómicos del entorno."

Considerando-se ainda a origem histórica do instrumento, pode-se elencar seu aparecimento no final da década de 60, nos Estados Unidos, com a nomenclatura National Environmental Protection Act (NEPA). "Inicialmente, a sua ideia era a criação de métodos obrigatórios que levassem em consideração aspectos culturais, históricos e ecológicos para o desenvolvimento de determinada atividade."21 Mas passou a tomar força nos anos 80, pois passou a se tornar exigência do Banco Mundial para o financiamento de projetos nos países subdesenvolvidos, tendo sido esta a principal influência do legislador brasileiro.

Apesar de já ter sido tratado anteriormente à Constituição Federal de 1988, em legislação e normativas infraconstitucionais, tem-se que essa foi a pioneira das constituições a tratar sobre esse estudo, especificamente ao que prevê no seu artigo 225, parágrafo $1^{\circ}$, inciso IV, in verbis:

Art. 225. [...]

Parágrafo $1^{\circ}$. Para assegurar a efetividade desse direito, incumbe ao Poder Público:

$[\ldots]$

IV - exigir, na forma da lei, para instalação de obra ou atividade potencialmente causadora de significativa degradação do meio ambiente, estudo prévio de impacto ambiental, a que se dará publicidade. (grifo nosso)

Paulo Bessa Antunes 22 ainda comenta que "No

19 ANTUNES, Paulo de Bessa. Direito ambiental. 9. ed. Rio de Janeiro: Lumen Júris, 2006. p. 283.

20 CANTER, Larry W. Manual de evolución de estúdios de impacto. Madrid: McGraw Hill, 1997. p. 2-3.

21 DEMARCHI, Felipe Camapnha; TRENTINI, Flávia. Estudo de impacto ambiental: apreciação crítica sobre a sua efetividade. In: BENJAMIM, Antonio Herman. (Org.) Anais do Congresso Brasileiro de Direito Ambiental. 2011. v. 3. p. 613.

22 ANTUNES, Paulo de Bessa. Direito ambiental. 9. ed. Rio de 
Brasil, a obrigatoriedade do prévio estudo de impacto ambiental para a implantação de projetos potencial ou efetivamente poluidores é uma imposição constitucional."

Conforme estabelece a Carta Magna, o estudo prévio de impacto ambiental (EPIA) deverá ser exigido para a instalação de qualquer obra ou atividade potencialmente causadora de significativa degradação ambiental. Caberá ao Poder Público exigi-lo, na forma da lei, com o objetivo de avaliar a dimensão das possíveis alterações que determinado empreendimento poderá causar ao meio ambiente. ${ }^{23}$

Para José Afonso da Silva ${ }^{24}$, o objetivo principal do EIA seria o de

[...] avaliar as proporções das possíveis alterações que um empreendimento, público ou privado, pode ocasionar ao meio ambiente. Trata-se de um meio de atuação preventiva, que visa a evitar as consequências danosas, sobre o ambiente, de um projeto de obras, de urbanização ou de qualquer atividade.

E nesse viés já se elenca que sua natureza jurídica seria, então, preventiva, “[...] o que o torna um dos mais importantes instrumentos da política de defesa da qualidade ambiental." 25

Por fim, somente é importante salientar que na verdade o Estudo de Impacto Ambiental tem ligação com o Licenciamento Ambiental, de modo que este último depende do primeiro para sua validade.

Diante de todas essas considerações, observa-se ser claro que o Estudo de Impacto Ambiental é ferramenta essencial para a manutenção ambiental e o melhor alcance do desenvolvimento sustentável, porém é uma ferramenta com campo relativamente limitado, pois só faz referência a empreendimento específico e só é utilizada quando requerida pelo dono do próprio empreendimento, que, inclusive, arcará com seus custos.

Sendo neste condão que surgiria a importância da Avaliação Ambiental Estratégica, assunto do próximo item, por ser esta de caráter mais abrangente, de iniciativa também do poder público e que poderia facilitar, até mesmo, o desenvolvimento dos Estudos de Impactos Ambientais, au-

Janeiro: Lumen Júris, 2006. p. 275.

23 CANOTILHO, Joaquim Gomes; LEITE, José Rubens Morato. (Org.) Direito constitucional ambiental brasileiro. São Paulo: Saraiva, 2007. p. 243.

24 SILVA, José Afonso da. Direito ambiental constitucional. 6. ed. São Paulo: Malheiros, 2007. p. 288-289.

25 CANOTILHO, Joaquim Gomes; LEITE, José Rubens Morato. (Org.) Direito constitucional ambiental brasileiro. São Paulo: Saraiva, 2007. p. 243. mentando as possibilidades do alcance da sustentabilidade.

\section{A importância da avaliação ambiental estra- tégica - AAE}

Feitas essas considerações iniciais, passa-se a adentrar no tema principal do artigo, qual seja a importância da aplicação da Avaliação Ambiental Estratégica no Brasil, considerando, então, seu conceito, objetivo e onde ela já é aplicada, para que se possa realizar uma diferenciação dos instrumentos já existentes no ordenamento jurídico brasileiro e sua consequente possibilidade de implementação.

Pode-se dizer que a Avaliação Ambiental Estratégica é "[...] uma ferramenta que fornece oportunidades para a formulação de políticas, planos e programas mais sensíveis às questões ambientais; facilita a integração e coordenação entre vários atores institucionais; e aumenta e fortalece a participação pública."26

Deve-se ter em mente que a Avaliação Ambiental Estratégica tem o dever de discutir políticas públicas, não sendo apenas um instrumento para justificá-las, “[...] necessitando estar articulada com seu processo de formulação, a fim de subsidiar a tomada de decisão frente a alternativas viáveis e sua comparação."27

La Evaluación Ambiental Estratégica nace como una herramienta de planificación que permite superar las limitaciones de La Evaluación de Impacto Ambiental clásica. Este se ocupa de proyectos concretos, incluidos los proyectos portuarios y se centra en la corrección de sus consecuencias. La EAE se enfoca en la fase de planificación, al pretender la evaluación de los planes y programas que afecten a una parcela determinada del territorio. La evaluación del medio que sugiere no es sino una evaluación de la sostenibilidad (ambiental, económica y social) de dichos planes. ${ }^{28}$

PELLIN, Angela et al. Avaliação Ambiental Estratégica no Brasil: considerações a respeito do papel das agências multilaterais de desenvolvimento. Engenharia Sanitária e Ambiental, Rio de Janeiro, v. 16, n. 1, mar. 2011. Disponível em: <http://www.scielo.br/scielo.php?script=sci_arttext\&pid=S1413-41522011000100006\&lang=pt $>$ Acesso em: 20 mar. 2012.

27 MACIEL, Marcela Albuquerque. Políticas públicas e desenvolvimento sustentável: Avaliação ambiental estratégica como instrumento de integração da sustentabilidade ao processo decisório. CONGRESSO BRASILEIRO DE DIREITO AMBIENTAL, 2011, Anais ... São Paulo: Imprensa Oficial do Estado de São Paulo, 2011. v. 1. p. 463.

28 CONAMA VII. La sostenibilidad em lós puertos.. Palacio Municipal de Congresos. 2004. Disponível em: <http:// 
$\mathrm{Na}$ realidade, a Avaliação Ambiental Estratégica vem a se diferenciar dos demais instrumentos de controle ambiental devido à sua amplitude sua ligação com as políticas públicas e a governança ambiental, ligando-se diretamente com políticas, planos e programas, conhecido no mundo doutrinário ambiental como "PPP's", e nesse sentido Riki Therivel e Maria Partidário ${ }^{29}$ desenvolvem um conceito bastante básico e direto: "Avaliação Ambiental (AA) de uma ação estratégica: uma política, plano ou programa."

Levando em consideração, porém, a abrangência da Avaliação Ambiental Estratégica, característica diferenciadora, principalmente, do Estado de Impacto Ambiental, elenca-se o conceito dado por Maria Partidário ${ }^{30}$

Processo formalizado de avaliação, no estágio mais antecipado possível, dos impactos ambientais de decisões tomadas nos níveis de política, planejamento e programa. A AAE considera uma faixa de possíveis alternativas em uma forma que é sistemática e assegura a plena integração de relevantes questões no ambiente inteiro, incluindo considerações biofísicas, econômicas, sociais e políticas.

A verdade é que, conforme pode-se observar pelos conceitos já apresentados, a Avaliação Ambiental Estratégica tem forte ligação com a Avaliação de Impacto Ambiental, na realidade ambas possuem as mesmas origens, que remontam aos princípios e conceitos de Avaliação de Impacto Ambiental norte americanos, “[...] onde as experiências adquiridas com sua implementação muito contribuíram para o desenvolvimento das etapas e procedimentos dos processo de AAE." 31

Contudo, deve-se ter em mente, conforme comentado no item anterior, que a Avaliação de Impacto Ambiental é gênero, do qual decorrem diversas espécies, podendo-se enquadrar, dessa maneira a Avaliação Ambiental Estratégica como uma delas, destacando-se, inclusive, que esta se utiliza dos princípios daquela, porém com metodologia e objetivos diferenciados.

www.conama.org > Acesso em: 22 mar. 2012.

29 THERIVEL, Riki; PARTIDARIO, Maria R. Introduction. In: THERIVEL, Riki; PARTIDÁRIO, Maria R. (Ed.) The practice of strategic environmental assessment. London: Earthscan, 1996. p. 4.

30 PARTIDÁRIO, Maria R. Strategic environmental assessment: key issues emerging from recent practice. Environmental impact assessment review, v. 16, p. 31-55, 1996. p. 31.

31 GONÇALVES, Luiz Claudio. Planejamento de energia e metodologia de avaliação ambiental estratégica: conceitos e críticas. Curtitiba: Juruá, 2009. p. 76.
"A AAE fundamenta-se nos princípios da avaliação de impacto ambiental (IAIA/IEA, 1999), constituindo, porém, um novo instrumento de gestão ambiental [...]"32

Dessa maneira, importante é destacar os critérios diferenciadores da Avaliação Ambiental Estratégica ante aos demais instrumentos de proteção ambiental, sendo que salienta-se que o foco principal será a diferenciação com o Estudo de Impacto Ambiental, instrumento que mais se aproxima daquela.

Portanto, elenca-se primariamente o objetivo da Avaliação Ambiental Estratégica, considerando-se que o do Estudo de Impacto Ambiental já foi elencado no item anterior.

Maria Partidário ${ }^{33}$ considera que o objetivo da Avaliação Ambiental Estratégica é

[...] facilitar a integração ambiental e a avaliação de oportunidades e riscos de estratégia de ação no quadro de um desenvolvimento sustentável. As estratégias de ação estão fortemente associadas à formulação de políticas, e são desenvolvidas no contexto de processos de planejamentos e programação.

O Ministério do Meio Ambiente Brasileiro também traça considerações acerca do objetivo da Avaliação Ambiental Estratégica em sua apostila elaborada especificamente sobre o assunto ${ }^{34}$ com o objetivo de atender à Agenda de Prioridades do referido Ministério, que determina o aprimoramento do licenciamento ambiental e dos demais instrumentos de política e gestão ambiental $^{35}$, nesse senti-

32 BRASIL. Ministério do Meio Ambiente. Avaliação ambiental estratégica. Brasília: MMA/SQA, 2002. p. 15.

33 PARTIDÁRIO, Maria R. Guia de boas práticas para avaliação ambiental estratégica: orientações metodológicas. Amadora: Agência Portuguesa de Ambiente, 2007. p. 9.

34 BRASIL. Ministério do Meio Ambiente. Avaliação ambiental estratégica. Brasília: MMA/SQA, 2002.

35 Foi elaborado um estudo de Avaliação Ambiental Estratégica como parte do Programa de Fortalecimento Institucional para o Licenciamento Ambiental, sendo que a referida apostila visa a consolidar os resultados do trabalho Estudos para Elaboração do Manual de Avaliação Ambiental Estratégica (AAE). Em palavras do texto da própria apostila: “O presente estudo constitui a primeira abordagem do MMA sobre o tema avaliação ambiental estratégica, tendo como objeto divulgá-lo para profissionais do Governo e da iniciativa privada e, como segundo, motivar dos meios acadêmicos e governamentais para o seu desenvolvimento, com vistas à sua adoção gradual no âmbito dos processos de planejamento dos diferentes setores de governo. Para isto, apresenta a síntese dos conceitos fundamentais e do conhecimento técnico básico sobre o assunto, a experiência de aplicação da avaliação ambiental na formulação de políticas, planos e programas em diversos países, na União Eu- 
do, segundo o Ministério do Meio Ambiente Brasileiro, o objetivo da Avaliação Ambiental Estratégica é:

[...] auxiliar, antecipadamente, os tomadores de decisões no processo de identificação e avaliação dos impactos e efeitos, maximizando os positivos e minimizando os negativos, que uma dada decisão estratégica - a respeito da implementação de uma política, um plano ou um programa - poderia desencadear no meio ambiente e na sustentabilidade do uso dos recursos naturais, qualquer que seja a instância de planejamento. $^{36}$

Por todas essas considerações observa-se que a Avaliação Ambiental Estratégica é instrumento bastante amplo, ligado às Políticas Públicas e à governança, constituindo-se como importante ferramenta de gestão ambiental, como já comentado anteriormente, sendo assim elenca-se a conceituação de Fischer ${ }^{37}$, que bastante retrata tal comentário:

Processo sistemático, voltado a objetivos, baseado em evidências, proativo e participativo, de apoio à tomada de decisão para a formulação de políticas, planos e programas sustentáveis, levando a uma melhor governança; [...] um instrumento de apoio à preparação de políticas, planos e programas que é concebido para adicionar rigor científico à tomada de decisão, aplicando uma série de métodos e técnicas adequadas; um framework sistemático de tomada de decisão, que estabelece um foco substantivo, particularmente em termos de alternativas e aspectos a serem considerados, dependendo do nível sistemático (política, plano ou programa), nível administrativo (nacional, regional, local) e setor de aplicação.

Coadunando, então, tais informações com as do item anterior pode-se observar que o Estudo de Impacto Ambiental, na verdade, é mais restrito, prestando-se basicamente a identificar e quantificar os impactos de projetos isoladamente, já a Avaliação Ambiental Estratégica é mais ampla, relacionando-se com políticas, planos, programas e projetos de ações estatais.

Nesse aspecto se revela a importância da implementação da Avaliação Ambiental Estratégica na legislação federal brasileira, pois, conforme comenta Cristiane

ropéia, no Banco Mundial e no Brasil, e oferece sugestões sobre as medidas e os procedimentos necessários para sua prática no contexto de alguns setores de governo." BRASIL. Ministério do Meio Ambiente. Avaliação ambiental estratégica. Brasília: MMA/SQA, 2002. p. 10.

36 BRASIL. Ministério do Meio Ambiente. Avaliação ambiental estratégica. Brasília: MMA/SQA, 2002. p. 13.

37 FISCHER, T. B. Theory and practice of strategic environmental assessment: towards a more systematic approach. London: Earthscan, 2007. p. 6.
Souza ${ }^{38}$ "O EIA não está cumprindo a sua função de, por exemplo, analisar os projetos em relação as suas alternativas e verificar, qual a alternativa de menor impacto. $\mathrm{O}$ EIA é para projetos, a lógica é diferente."

Não se deve desmerecer o Estudo de Impacto Ambiental, mas sim deve-se estudar mais a fundo a Avaliação Ambiental Estratégica, como possível ferramenta a ser usada em nosso ordenamento jurídico.

\subsection{Considerações dos países e estados brasileiros que já utilizam a Avaliação Ambiental Estraté- gica}

Como já comentado no início do trabalho, a Avaliação Ambiental Estratégica já é aplicada em diversos países, porém ainda não possui, no Brasil, legislação federal específica, apesar de alguns estados brasileiros já a utilizarem por meio de normativas e estruturas formadas pelos mesmos.

Conforme pesquisa elaborada por Fernandes e $\mathrm{Pa}$ rada $^{39}$, apresentada no artigo "A Avaliação Ambiental Estratégica de planos e programas do sector eléctrico: práticas mundiais e a experiência da rede eléctrica nacional”, o qual foi publicado no XIII Encuentro Regional Iberoamericano de Cigré, realizado na Argentina, considerando o enquadramento internacional da Avaliação Ambiental Estratégica, pode-se considerar a seguinte tabela:

8 SOUZA, Cristiane Mansur de Moraes. Avaliação ambiental estratégica (AAE): limitações dos estudos de impacto ambiental (EIA). In: SIMPÓSIO BRASILEIRO DE RECURSOS HÍDRICOS, 17. São Paulo. Disponível em: <www. abrh.org.br/nov/xcii_simp_bras_rec_hidric_sao_paulo_041.pdf> Acesso em: 25 fev. 2013.

39 FERNANDES, P.; PARADA, F. A Avaliação Ambiental Estratégica de planos e programas do sector eléctrico: práticas mundiais e a experiência da rede eléctrica nacional. In: ENCUENTRO REGIONAL IBEROAMERICANO DE CIGRÉ, 13. Porto Iguaçu - Argentina, 2009. Disponível em: <http://www.labplan.ufsc.br/congressos/XIII\%20Eriac/ C3/C3-04.pdf> Acesso em: 25 fev. 2013. 


\section{Tabela 1 - Enquadramento regulamentar da} amostra de países

\begin{tabular}{c|c}
\hline $\begin{array}{c}\text { Tipo de enquadramento } \\
\text { regulamentar }\end{array}$ & Países \\
\hline $\begin{array}{c}\text { AAE definida em legis- } \\
\text { lação específica }\end{array}$ & $\begin{array}{c}\text { Portugal, Espanha, França, } \\
\text { Bélgica, Itália, Reino } \\
\text { Unido, }\end{array}$ \\
$\begin{array}{c}\text { Suécia, República Checa, } \\
\text { Polónia, Estónia, Canadá, } \\
\text { Brasil }\end{array}$ \\
\hline $\begin{array}{c}\text { AAE integrada na legis- } \\
\text { lação pré-existente de } \\
\text { Avaliação de Impacte } \\
\text { Ambiental (AIA) }\end{array}$ & $\begin{array}{c}\text { Holanda, Alemanha, Fin- } \\
\text { lândia, China }\end{array}$ \\
\hline $\begin{array}{c}\text { AAE integrada em legis- } \\
\text { lação enquadradora ou } \\
\text { temática }\end{array}$ & $\begin{array}{c}\text { Áustria, Nova Zelândia, Es- } \\
\text { tados Unidos da América }\end{array}$ \\
\hline
\end{tabular}

Fonte: FERNANDES, P.; PARADA, F. A Avaliação Ambiental Estratégica de planos e programas do sector eléctrico: práticas mundiais e a experiência da rede eléctrica nacional. ENCUENTRO REGIONAL IBEROAMERICANO DE CIGRÉ, 13. Porto Iguaçu - Argentina, 2009. Disponível em: <http://www.labplan.ufsc.br/ congressos/XIII\%20Eriac/C3/C3-04.pdf> Acesso em: 25 de fevereiro de 2013.

Porém, após pesquisa bibliográfica para o presente artigo científico ainda se realizaria o acréscimo da Dinamarca no último quadro, sendo que a Avaliação Ambiental Estratégica neste país está integrada à legislação enquadradora. ${ }^{40}$

Assim como se retiraria o Brasil da primeira categoria, pois apesar de alguns estados já aplicarem a Avaliação Ambiental Estratégica com legislações específicas, ainda não há legislação federal que a regulamente, apenas um Projeto de Lei que tramita no Congresso Federal de número 2072, datado de 2003.

Porém, de qualquer forma, considerando a referida tabela já pode-se observar que a Avaliação Ambiental Estratégica é bastante aplicada mundialmente, considerando-se que $63 \%$ dos países que a aplicam já possuem legislação específica sobre o tema.

Focando-se em aspecto nacional, pode-se elencar o já referido Projeto de Lei que tramita no Congresso Nacional desde o ano de 2003, e que tem como foco principal a regulamentação da Avaliação Ambiental Estratégica de políticas, planos e programas, seguidas de modificação na lei da Política Nacional do Meio Ambiente - PNMA.

Ademais, como já comentado, alguns estados brasileiros já a implementam nas suas gestões, como é o caso

40 BRASIL. Ministério do Meio Ambiente. Avaliação ambiental estratégica. Brasília: MMA/SQA, 2002. p. 30-33. claro de São Paulo e Minas Gerais.

No estado de Minas Gerais a Secretaria de Estado de Meio Ambiente e Desenvolvimento Sustentável - SEMAD teve a iniciativa de criar um projeto de implementação da Avaliação Ambiental Estratégica, onde cria os Núcleos de Gestão Ambiental - NGA por meio do Decreto $\mathrm{n}^{\circ}$. 43.372/2003, que possui como uma de suas funções a elaboração da Avaliação Ambiental Estratégica.

Na proposta de implantação do programa ${ }^{41}$, o Governo do Estado elenca, então, o conceito de Avaliação Ambiental Estratégica, seu objetivos, quais suas principais características, quais as etapas, qual sua finalidade e as vantagens de sua implementação.

No estado de São Paulo, também está havendo a aplicação do instrumento desde o ano de 1994, quando foi criada a Resolução no 44 de 29 de dezembro do CONSEMA.

Na realidade o estado de São Paulo é o que mais efetivamente aplica a Avaliação Ambiental Estratégica, sendo que algumas de suas experiências práticas são apontadas até mesmo pela Apostila do Ministério do Meio Ambiente ${ }^{42}$ já comentada, podendo-se destacar:

- o Estudo de Impacto Ambiental do Programa de corredores de ônibus da prefeitura de São Paulo;

- a criação da usina hidrelétrica de Tijuca Alto;

- o programa de despoluição do Rio Tietê;

- a criação do Rodoanel Metropolitano.

Estes são apenas alguns exemplos de aplicação da Avaliação Ambiental Estratégica no estado de São Paulo. Ademais, o Ministério do Meio Ambiente ainda destaca mais dois projetos federais em que o instrumento foi utilizado: no projeto do gasoduto Bolívia - Brasil, tendo sido esta uma exigência do Banco Mundial; e nos diversos projetos de geração de energia elétrica nas bacias hidrográficas dos Rios Tocantins e Tibagi.

Considerando-se, então, todos os países que efetivamente usam o instrumento e os resultados apresentados, inclusive no Brasil, já se pode observar a importância que a Avaliação Ambiental Estratégica apresenta, isso sem considerar que conforme pesquisado, todos os países

41 MINAS GERAIS. Secretaria de Estado de Meio Ambiente e Desenvolvimento Sustentável do Estado de Minas Gerais. Proposta de implantação da Avaliação Ambiental Estratégica. Minas Gerais, 2003. Disponível em: <www.meioambiente.mg.gov.br/images/stories/coisas/aae_apostila.pdf> Acesso em: 25 fev. 2013.

42 BRASIL. Ministério do Meio Ambiente. Avaliação ambiental estratégica. Brasília: MMA/SQA, 2002. p. 44-46. 
e estados que a aplicam apenas apontam vantagens, das quais se procurará compilar no próximo subitem.

\subsection{Considerações das vantagens da implementa- ção da Avaliação Ambiental Estratégica}

Fernandes e Parada são portugueses, e em artigo científico elaborado sobre Avaliação Ambiental Estratégica, já mencionado neste trabalho, traçam algumas considerações de vantagens já consideradas. Vale destacar que Portugal é um dos países que apresenta legislação específica sobre o tema desde o ano de 2007, quando passou a implementá-la na gestão ambiental, é o Decreto-Lei n ${ }^{\circ}$. 232/2007, de 15 de junho. Desse modo se apresenta as vantagens apresentadas pelos referidos autores:

A aplicação da AAE constitui uma mais-valia pois permite:

- Discutir alternativas numa fase em que opções estratégicas ainda são possíveis;

- Considerar os impactes cumulativos de projectos subsidiários em vez dos impactes de cada projecto de forma individual;

- Antecipar os constrangimentos que podem ocorrer ao nível do projecto, facilitando a sua resolução dentro do planeamento definido;

- Integrar a participação pública nas decisões estratégicas sobre planos e programas;

- Analisar diferentes cenários de desenvolvimento e identificar soluções alternativas;

- Facilitar a identificação e comparação dos potenciais impactes significativos no ambiente e noutras vertentes (ex: económica e social). ${ }^{43}$

Luiz Claudio Gonçalves ${ }^{44}$ em seu livro também aponta vantagens consideráveis à sua aplicação, destacando primordialmente que a "[...] AAE tende a ser um vetor de promoção da sustentabilidade para o processo de planejamento e desenvolvimento de um país.” E complementa afirmando que tudo isso é devido pois a Avaliação Ambiental Estratégica tem como função primordial estimular a implementação de práticas e procedimentos que ajudam a promover o desenvolvimento sustentável.

43 FERNANDES, P.; PARADA, F. A Avaliação Ambiental Estratégica de planos e programas do sector eléctrico: práticas mundiais e a experiência da rede eléctrica nacional. In: ENCUENTRO REGIONAL IBEROAMERICANO DE CIGRÉ, 13. Porto Iguaçu - Argentina, 2009. Disponível em: <http://www.labplan.ufsc.br/congressos/XIII\%20Eriac/ C3/C3-04.pdf> Acesso em: 25 fev. 2013.

44 GONÇALVES, Luiz Claudio. Planejamento de energia e metodologia de avaliação ambiental estratégica: conceitos e críticas. Curtitiba: Juruá, 2009. p. 87-88.
O Ministério do Meio Ambiente brasileiro também apresenta em sua apostila os benefícios que podem ser esperados com a aplicação da Avaliação Ambiental Estratégica, quais sejam:

- visão abrangente das implicações ambientais da implementação das políticas, planos e programas governamentais, sejam eles pertinentes ao desenvolvimento setorial setoriais ou aplicados a uma região;

- segurança de que as questões ambientais serão devidamente tratadas;

- facilitação do encadeamento de ações ambientalmente estruturadas;

- processo de formulação de políticas e planejamento integrado e ambientalmente sustentável;

- antecipação dos prováveis impactos das ações e projetos necessários à implementação das políticas e dos planos e programas que estão sendo avaliados; e

- melhor contexto para a avaliação de impactos ambientais cumulativos potencialmente gerados pelos referidos projetos.

Por todas essas considerações, além de tantas outras que pode-se encontrar na doutrina ambiental nacional e mundial, já se consegue perceber a importância da aplicação da Avaliação Ambiental Estratégica, sendo que o que resta ser entendido é a possibilidade, ou não, de sua aplicação no ordenamento jurídico brasileiro em âmbito federal, com regulamentação específica, de modo que possa se afirmar que a Avaliação Ambiental Estratégica compõe um dos instrumentos de garantia da sustentabilidade, incorporando o arcabouço legal nacional.

\section{A possibilidade da aplicação da avaliação ambiental estratégica no ordenamento jurí- dico brasileiro}

Com o estado de degradação ambiental que se chegou ao Brasil, assim como no mundo, quase todo processo de urbanização acaba apresentando algum risco ambiental, portanto, necessária é a implementação de políticas públicas assim como a consideração de utilização de instrumentos que controlem o avanço urbano, tecnológico e até mesmo turístico, com vistas a garantia da sustentabilidade, sendo um destes a Avaliação Ambiental Estratégica.

No Brasil, como já comentado, a Avaliação Ambiental Estratégica já é aplicada em alguns estados e com efetivos resultados, sendo que até mesmo o Ministério do Meio Ambiente considera como sendo importante a sua 
implementação no ordenamento jurídico brasileiro, para que esta possa ser regulamentada e efetivamente aplicada.

O Ministério buscou, com efetividade, chamar a atenção da comunidade acadêmica e legislativa brasileira para o uso da Avaliação Ambiental Estratégica no Brasil, publicando uma apostila com dados básicos da mesma no ano de 2002, conforme já comentado alhures, sendo que neste material ele apresenta até mesmo o avanço do instrumento em alguns países que há sua aplicação.

A partir disso houve, ainda, o desenvolvimento de um programa de capacitação de Avaliação Ambiental Estratégica, que tem como objetivo atingir quadros técnicos governamentais a partir de casos pilotos reais. ${ }^{45}$

Por tudo isto, o presente momento político-institucional do Brasil pode ser considerado como favorável para a inovação metodológica dos processos de proposição e decisão de políticas públicas e suas estratégias de implementação, por meio da implantação da AAE. ${ }^{46}$

Ademais, a Avaliação Ambiental Estratégica poderia fomentar o crescimento de diversos setores da economia, como por exemplo, agricultura, floresta, pesca, energia, indústria, transporte, saneamento básico, turismo, gerenciamento de águas, telecomunicações, planejamento de solo urbano e rural, por meio da criação de políticas, planos e programas que visassem o seu avanço considerando a mantença da sustentabilidade, como já realizado em diversos países com resultados positivos.

Oliveira e Souza ${ }^{47}$ ainda apontam que "[...] apesar de existirem várias razões que contribuem na prática da AIA no Brasil, especialmente questões políticas, institucionais e operacionais, seguramente o fato do EIA estar 'sobrecarregado' em suas funções contribui para essa situação."

Nesse sentido, o que se pode observar é que a implementação da Avaliação Ambiental Estratégica representaria um grande avanço nas técnicas de alcance da sustentabilidade, pois lida com questões mais amplas do

45 SOUZA, Cristiane Mansur de Moraes. Avaliação ambiental estratégica (AAE): limitações dos estudos de impacto ambiental (EIA). In: SIMPÓSIO BRASILEIRO DE RECURSOS HÍDRICOS, 13. São Paulo. p. 9. Disponível em: $<$ www.abrh.org.br/nov/xcii_simp_bras_rec_hidric_sao_ paulo_041.pdf> Acesso em: 25 fev. 2013.

46 BRASIL. Ministério do Meio Ambiente. Avaliação ambiental estratégica. Brasília: MMA/SQA, 2002. p. 66.

47 OLIVEIRA, I. S. D.; SOUZA, M. P. A. A contribuição do zoneamento ambiental para o estudo de impacto ambiental. In: ESPÍNDOLA, E. V. G.; WENDLAND, E. (Org.) PPG-SEA: trajetórias e perspectivas de um curso multidisciplinar. São Carlos: RiMa, 2005. p. 137-154. que o Estudo de Impacto Ambiental, que é bastante específico, suprindo, desta forma, as limitações apresentadas por este, de forma que pudesse se atingir o real objetivo das Avaliações de Impactos Ambientais apresentada pela Política Nacional do Meio Ambiente.

\section{Considerações finais}

Não restam dúvidas na atualidade da necessidade da proteção ambiental, discussão que já vem sendo traçada há várias décadas, porém, é evidente que para o alcance dessa proteção fazem-se necessárias várias atitudes que são pertinentes ao poder público, às empresas e à sociedade civil, os quais devem preocupar-se com uma efetiva gestão ambiental, sendo que para a efetivação concreta dessa proteção ambiental existe a necessidade da aplicação de certos instrumentos reguladores que visam a garantia da sustentabilidade.

No viés ambiental, considerando-se, então, tais instrumentos, pode-se destacar a Avaliação de Impactos Ambientais, instrumento genérico tratado, no Brasil, pela Política Nacional do Meio Ambiente. Nesse sentido, tendo em vista seu caráter genérico considera-se ser, este, gênero, do qual se desdobram diversas espécies.

No Brasil sua principal espécie, a mais aplicada, é o Estudo de Impacto Ambiental, previsto constitucionalmente no artigo 225 da Carta Magna, porém tal instrumento é de alcance limitado, pois visa atender projetos específicos gerados pela iniciativa do particular. Tendo em vista essa característica principal, ele, atualmente, está sobrecarregado e com aplicabilidade ineficiente em alguns setores, sendo que por tal motivo necessária é a apresentação de algumas soluções.

Uma dessas soluções seria a Avaliação Ambiental Estratégica, instrumento que também segue os mesmos princípios da Avaliação de Impactos Ambientais e é aplicada e regulamentada em diversos países, sendo que em todos são apresentadas diversas vantagens em sua aplicação.

Já existe um Projeto de Lei tramitando no Congresso Nacional com vistas a criação de uma lei específica sobre o tema, de modo a regulamentá-lo para possibilitar sua aplicação em todo o território brasileiro.

Os estados de São Paulo e Minas Gerais já utilizam a Avaliação Ambiental Estratégica através da criação de normativas próprias e órgãos regulamentadores, sendo que já apresenta, significativos avanços quanto a sua aplicação. Há, também, interesse pelo Ministério do Meio 
Ambiente para a sua aplicação, sendo que já realizou a criação de um material que explica o que seria a Avaliação Ambiental Estratégica, além de apresentar diversas vantagens para a sua aplicação.

Por tudo isso, o que se observa é que a Avaliação Ambiental Estratégica se apresenta como importante instrumento de gestão ambiental ligado a políticas, planos e programas que visam resguardar a sustentabilidade por meio de uma boa governança ambiental, sendo que sua regulamentação específica no Brasil, através de uma legislação federal, seria de grande valia para o alcance da sustentabilidade.

\section{Referências}

ANTUNES, Paulo de Bessa. Direito ambiental. 9. ed. Rio de Janeiro: Lumen Júris, 2006.

CANOTILHO, Joaquim Gomes; LEITE, José Rubens Morato. (Org.) Direito constitucional ambiental brasileiro. São Paulo: Saraiva, 2007.

CANTER, Larry W. Manual de evolución de estúdios de impacto. Madrid: McGraw Hill, 1997.

DECLARAÇÃO do Rio sobre meio ambiente e desenvolvimento. Rio de Janeiro, 1992. Disponível em: <http://www.ufa.br/npadc/gpeea/DocsEA/ DeclaraRioMA.pdf $>$. Acesso em: 20 mar. 2012.

DEMARCHI, Felipe Camapnha; TRENTINI, Flávia. Estudo de impacto ambiental: apreciação crítica sobre a sua efetividade. In: BENJAMIM, Antonio Herman. (Org.) Anais do Congresso Brasileiro de Direito Ambiental. PNMA: 30 anos da Política Nacional de Meio Ambiente. São Paulo: Imprensa Oficial do Estado de São Paulo, 2011.

ESTEVAN BOLEA, M. T. Evalución del impacto ambiental. Madrid: ITSEMAP (MAPFRE), 1989.

FERNANDES, P.; PARADA, F. A Avaliação Ambiental Estratégica de planos e programas do sector eléctrico: práticas mundiais e a experiência da rede eléctrica nacional. In: ENCUENTRO REGIONAL IBEROAMERICANO DE CIGRÉ, 13. Porto Iguaçu Argentina, 2009. Disponível em: <http://www.labplan. ufsc.br/congressos/XIII\%20Eriac/C3/C3-04.pdf> Acesso em: 25 fev. 2013.

FISCHER, T. B. Theory and practice os strategic environmental assessment: towards a more systematic approach. London: Earthscan, 2007.

GRANZIERA, Maria Luiza Machado. Direito ambiental. São Paulo: Atlas, 2009.
GONÇALVES, Luiz Claudio. Planejamento de energia e metodologia de avaliação ambiental estratégica: conceitos e críticas. Curtitiba: Juruá, 2009.

CONAMA VII. La sostenibilidad em lós puertos.. Palacio Municipal de Congresos. 2004. Diponível em: <http:// www.conama.org >. Acesso em: 22 mar. 2012.

MACHADO, Paulo Affonso Leme. Direito ambiental brasileiro. 18. ed. São Paulo: Malheiros, 2010.

MACIEL, Marcela Albuquerque. Políticas públicas e desenvolvimento sustentável: avaliação ambiental estratégica como instrumento de integração da sustentabilidade ao processo decisório. CONGRESSO BRASILEIRO DE DIREITO AMBIENTAL, 2011, Anais ... São Paulo: Imprensa Oficial do Estado de São Paulo, 2011.

MARTÍN MATEO, Ramón. Tratado de derecho ambiental. Madrid: Editorial Trivium, 1991.

MILARÉ, Edis. A importância dos estudos de impacto ambiental. São Paulo: RT, 1988.

MILARÉ, Edis. Direito do ambiente: doutrina, prática, jurisprudência, glossário. 2. ed. São Paulo: RT, 2001.

BRASIL. Ministério do Meio Ambiente. Avaliação ambiental estratégica. Brasília: MMA/SQA, 2002.

OLIVEIRA, I. S. D; SOUZA, M. P. A. A contribuição do zoneamento ambiental para o estudo de impacto ambiental. In: ESPÍNDOLA, E. V. G.; WENDLAND, E. (Org.) PPG-SEA: trajetórias e perspectivas de um curso multidisciplinar. São Carlos: RiMa, 2005.

PARTIDÁRIO, Maria R. Guia de boas práticas para avaliação ambiental estratégica: orientações metodológicas. Amadora: Agência Portuguesa de Ambiente, 2007.

PARTIDÁRIO, Maria R. Strategic environmental assessment: key issues emerging from recent practice. Environmental impact assessment review, v. 16, p. 31-55, 1996.

PELLIN, Angela et al. Avaliação Ambiental Estratégica no Brasil: considerações a respeito do papel das agências multilaterais de desenvolvimento. Engenharia Sanitária e Ambiental, Rio de Janeiro, v. 16. n. 1, mar. 2011. Disponível em: $\quad<$ http://www.scielo.br/scielo.php?script=sci_ arttext\&pid $=$ S1413-41522011000100006\&lang $=$ pt $\quad>$. Acesso em: 22 mar. 2012.

MINAS GERAIS. Secretaria de Estado de Meio Ambiente e Desenvolvimento Sustentável do Estado de Minas Gerais. Proposta de implantação da Avaliação Ambiental Estratégica. Minas Gerais, 2003. Disponível em: <www. meioambiente.mg.gov.br/images/stories/coisas/aae_ 
apostila.pdf>. Acesso em: 25 fev. 2013.

SILVA, Américo Luís Martins. Direito do meio ambiente e dos recursos naturais. São Paulo: RT, 2004.

SILVA, José Afonso da. Direito ambiental constitucional. 6. ed. São Paulo: Malheiros, 2007.

SOUZA, Cristiane Mansur de Moraes. Avaliação ambiental estratégica (AAE): limitações dos estudos de impacto ambiental (EIA). In: SIMPÓSIO BRASILEIRO DE RECURSOS HÍDRICOS, 17. São Paulo. Disponível em: <www.abrh.org.br/nov/xcii_simp_bras_rec_hidric_ sao_paulo_041.pdf>. Acesso em: 25 fev. 2013.

THERIVEL, Riki; PARTIDARIO, Maria R. Introduction. In: THERIVEL, Riki; PARTIDÁRIO, Maria R. (Ed.) The practice of strategic environmental assessment. London: Earthscan, 1996. p. 4. 